\title{
Mitigating Barriers to Persistence: A Review of Efforts to Improve Retention and Graduation Rates for Students of Color in Higher Education
}

\author{
Tachelle Banks, $\mathrm{PhD}^{1} \&$ Jennifer Dohy, $\mathrm{PhD}^{1}$ \\ ${ }^{1}$ College of Education, Health and Human Services, Cleveland State University, Cleveland, Ohio, USA \\ Correspondence: Tachelle Banks, Department of Teacher Education, Cleveland State University, Cleveland, OH \\ 44115, USA. Tel: 1-216-687-4608. E-mail: t.i.banks@ @suohio.edu
}

Received: December 19, 2018

Accepted: January 4, 2018 Online Published: January 19, 2019

doi:10.5539/hes.v9n1p118

URL: https://doi.org/10.5539/hes.v9n1p118

\begin{abstract}
This literature review highlights barriers to persistence, retention, and graduation for students of color at institutions of higher learning. Successful strategies, approaches, and initiatives are discussed with consideration to deficit and strengths-based approaches. It is also highlighted that universities may need to address programmatic barriers within the institutions that may exacerbate systemic barriers to success for students of color in higher education.
\end{abstract}

Keywords: equity, higher learning, persistence, retention, strengths-based approach

\section{Current State of Retention of Students of Color in Institutions of Higher Learning in the United States}

The United States continues to become more diverse. As recognized by the United States Census (2010), between 2000 and 2010, a $43 \%$ growth in the Hispanic population, who comprise $16.3 \%$ of the total population, was reported (U.S. Census, 2010). In addition, African Americans represent 13\% of the total population and roughly 5\% of the population identified as Asians (U.S. Census, 2010). Access to and graduation from institutions of higher learning for all populations is imperative to creating a more equitable and democratic society (Duranczyk, Higbee, \& Lundell, 2004). Despite the increase in diversity, colleges and universities across the nation continue to struggle to provide, retain, and graduate students of color to the same degree as their White and Asian counterparts (Duranczyk et al, 2004).

Looking at national data regarding graduation rates by race, it is clear that disparities between students of color and their counterparts exist. Six-year completion rates at four-year institutions reveal that African American students were the least likely to graduate (45.9\%), followed by Hispanic students (55\%) (Shapiro, Dundar, Huie, Wakhungu, Yuan, Nathan, Hwang, 2017). White students had a graduation rate of 67.2\% and Asian students had the highest at $71.7 \%$ (Shapiro et.al., 2017). These disparities are not isolated to first year college students as completion rates of students transferring from community colleges also revealed differences by race. One in 4 Asian and 1 in 5 White transfer students graduated, while only 1 in 10 and 1 in 13 of Hispanic and Black students graduated, respectively (Shapiro et al., 2017).

To explain inequities, the achievement gap, or a focus on measurable outcomes, such as scores on standardized tests have dominated the national discourse for the past two decades (Welner \& Carter, 2013). This focus places the blame with the individual, rather than looking at the problem in a more comprehensive manner. Less attention has been paid to opportunities gaps or having access to resources and opportunities both in schools and outside of schools that allow for preparation for college, career readiness, and citizenship (Welner \& Carter, 2013). Opportunity gaps can exist in terms of health, housing, nutrition, safety, and enriching experiences (Welner \& Carter, 2013). We acknowledge that such opportunity gaps exist well before students enter institutions of higher learning, which can ultimately impact access and achievement. However, this paper is a literature review concerned with the opportunity gaps to persistence for students of color who are already enrolled in colleges and universities and ways to mediate against these disparities. Persistence can be considered ones' ability to remain enrolled (retention) or complete a degree at an institution of higher education (U.S. Department of Education; National Center of Educational Service, 2013).

Institutions of higher learning in the United States are charged with addressing the preexisting and current 
opportunity gaps that may impact academic performance and outcomes between students of color and their peers. However, many fall short of addressing inequities in terms of academic engagement and persistence (Keels, 2013; Duranczyk, Higbee \& Lundell, 2004). Frequently discussed, but rarely accomplished is the push to create more inclusive and diverse university environments that not only attract students of color but also retain and graduate them as well (Duranczyk et al., 2004). Many challenges exist to arriving at these objectives. On campus, miscommunications may exist between instructors or counselors, a lack of knowledge of resources and access to high quality mentorships, feelings of isolation, and stereotyping, to name a few, may create barriers to success for students of color (Dulabaum, 2016). In order to mediate against these barriers a number of universities have implemented programs in the form of deficit-remediation, where a college creates interventions based on the needs or perceived deficits of the students. They may seek to create feelings of belonging, access to high quality mentors, provide study related opportunities, and require remedial coursework. An alternative approach to this is a strength-based model that views all students as capable of success through the realization and application of their individual strengths. Less frequently discussed are barriers to retention and graduation rates of students of color in programming at the institutional level (Bohanon, 2018). This paper will discuss, in more depth, barriers to persistence for students of color and highlight programs developed to mediate against these opportunity gaps from the deficit-approach model as well as the strengths-based approach, followed by implications for policy development and practice with an emphasis on improving programming that may hinder students of color. The proceeding will begin by outlining opportunity gaps that exist in institutions of higher learning for students of color.

\section{Method}

The following literature review begins by outlining opportunity gaps in higher education and then considers how universities are addressing these issues. We wanted to focus on universities that have shown success in mitigating such barriers and viewed programs at universities in the United States and their associated data. In addition, the literature focus was solution-based, looking at whether universities were successful through the use of deficit-based or strengths-based approaches to opportunity gaps.

\section{Opportunity Gaps in Higher Education}

Reviewed literature regarding opportunity gaps in higher education tend to surround issues of racism as contributing to feelings of loneliness, disengagement, and, more specifically, as a barrier to retention and graduation for students of color. Assumptions are often made regarding disparities in college graduation rates of students of color that blame racial inferiority. In an extreme example, during a town hall meeting, Pennsylvanian Republican Sen. John Eichelberger of Blair County suggested that students of color attending inner city K-12 schools are being encouraged to attend college, but ultimately drop-out, and thus a less-intensive track may be more appropriate for them (Associated Press, 2017). This line of thinking, particularly when it is highlighted in political discourse, is one of the barriers that contributes to drop out rates, as students of color feel as though they do not belong in predominately white institutions of higher learning where they are often subjected to institutional, implicit, and blatant acts of racism from students and professors alike.

A New York Times Article (NYT) (2015) solicited personal stories of racism on American campuses. One student described an instance where a noose was hung at the student center and the University responded with emails of promises of a colorblind university (NYT, 2015). "Colorblindness" ignores cultural differences and is a form of implicit racism. Another student explained a conversation at their university where affirmative action was discussed as being useless due to its location in Roanoke, a predominately white area, as being undesirable to African American students (NYT, 2015). In another, a student explained how a white professor, citing cultural differences, had them read a poem written in the 1920s by a black composer. Research suggests that such instances of racism can lead students of color to feel as though they do not belong in institutions of higher learning, particularly at predominately White institutions, which can lead to disengagement, underperformance, and high dropout rates for students of color. In contrast to views of racial inferiority, students of color, when Grade Point Average (GPA) and SAT scores are taken into account, drop out at a higher degree than their White counterparts, suggesting that the issue may have more to do with racist ideals that persist in institutions of higher learning than the capability of the students.

Across the nation, university professors are predominately White, which leads to the maintenance of the status quo as well as a lack of variance in the curriculum and high-quality mentorship for students of color from faculty who look like them. The National Center for Educational Statistics (2015), for the Fall 2015 school year, provides data on the percentages of faculty at degree-granting Postsecondary institutions by race and gender (NCES, 2015). Forty-one percent of white males are employed as faculty at institutions of higher learning and 35\% 
are white females (NCES, 2015). In contrast, only 3\% are Black males and 3\% are Black females (NCES, 2015). Three percent of faculty across the nation are Hispanic men and $2 \%$ are Hispanic females (NCES, 2015). Having a predominately white faculty limits perspectives and cultural awareness, potentially creating a disconnect for students of color and increasing instances of implicit racism.

Students of color are often exposed to instances of microaggressions from their white professors where a belief may persist that they are intellectually inferior to Whites (Harper, Patton, \& Wooden, 2009). Physical, emotional and mental health issues may be related to microaggressions experienced on college campuses, which can derail a students' goal of graduating from a four-year institution, particularly on predominately White campuses (Moragne-Patterson \& Barnett, 2017). Students of color are hurt most by racist interactions with faculty and staff at their university, where a higher standard of acceptance is expected (Moragne-Patterson \& Barnett, 2017). Professors and staff, regardless of race, are expected by students of color to be more culturally aware and accepting than the students. Instances of implicit bias have implications with regard to student success as students may feel a lack of belonging, contributing to disengagement and dropout rates (Moragne-Patterson \& Barnett, 2017).

Dulabaum (2016) studied barriers to retention of African American and Hispanic Males at predominately white institutions using unstructured interviews. Students of color stated that they did not always relate to instructors, counselors and teachers, with one interviewee revealing feelings that professors do not care about students' success and fail to offer flexible office hours (Dulabaum, 2016). Flexibility is needed for students with families and who work (Dulabaum, 2016). African American males self-reported that they felt stereotyped and discriminated against, viewed by professors and not belonging and incapable of success (Dulabaum, 2016). This same finding has been noted in other research as well.

Moragne-Patterson and Barnett (2017) conducted a qualitative study to determine the experiences of African American and their interpretations of racial and gender-based microaggressions. Findings revealed, that on predominately White campuses, African American students reported feelings of isolation, a lack of institutional support, and having to prove intellectual capability, to name a few (Moragne-Patterson \& Barnett, 2017). In terms of institutional support, many students reported that they were surprised by the microaggressions from faculty (Moragne-Patterson \& Barnett, 2017). In one instance, an African American student was accused by their professor of cheating because their test revealed a high score (Moragne-Patterson \& Barnett, 2017). The student had to retake the test in a room while being monitored by a graduate assistant (Moragne-Patterson \& Barnett, 2017). Loneliness is related to having little to no interactions with students and faculty of color and the perception that they were not as capable as White students (Moragne-Patterson \& Barnett, 2017). Students of color explained the exhaustion they felt constantly trying to prove themselves, despite their previous records of success (Moragne-Patterson \& Barnett, 2017). Self-reported obstacles for students of color also include access to and understanding of financial resources (Dulabaum, 2016).

Since the mid-90s, student's graduation rates of students from the bottom $40 \%$ of U.S. households have remained at under $12 \%$ of new college graduates (Bohanon, 2018). A lack of education regarding financial aid, including how to apply for and a where to appropriately use the money when aid is received (e.g. tutoring programs) can impede retention rates (Dulabaum, 2016). Government funded programs often require a student be enrolled in a high number of credit hours in order to be eligible for housing rates and insurance (Dulabaum, 2016). In fact, it is higher education systems that may be hindering economic and racial advancements through an emphasis on student deficits and remedial education, even when interventions to address financial burdens are addressed (Bohanon, 2018).

While financial assistance is necessary for low-income students to complete their college degrees, of the 7.3 million students, $60 \%$ of whom are from underrepresented groups, who receive the Pell Grant; about half of them do not obtain a baccalaureate degree in six years (Bohanon, 2018). This is particularly problematic as $80 \%$ of students that receive Pell Grants also take out loans and therefore, are responsible for repayment while having limited job opportunities without a degree (Bohanon, 2018). This number is particularly concerning for African American students who come from homes that have a net worth $10 \%$ of the average White households (Bohanon, 2018).

At the same time, students of color report being inadequately prepared for college level work, in terms of writing ability, computer literacy, time management, and study skills (Dulabaum, 2016). Struggles with self-motivation with a lack of initiative and passion for attending college was is also an indicated concern (Dulabaum, 2016). It does not help that low-income students, a majority of which are students of color, are more likely to be enrolled in remedial courses. Remedial education classes may discourage rather than promote graduation rates as 
enrollment in these courses are not a part of the credits necessary for graduation (Bohanon, 2018).

In this selection, a number of opportunity gaps were outlined that are embedded in the culture of institutions of higher learning that can impede the retention and graduation rates of students of color. Students of color that attend schools that are predominately White with a predominately White faculty body often experience instances of institutional, implicit, and blatant racism, resulting in feelings of isolation and disengagement. In addition, students also need support for deficits in writing and academic abilities that may be the result of their K-12 schooling, but nonetheless the responsibility of the university. However, students enrolled in remedial coursework are more likely to dropout. This is an institutional barrier that can be addressed by looking at current programming. In the proceeding we will examine initiatives that have been successful in promoting retention and graduation rates of students of color in order to develop a comprehensive, solution-based approach to addressing opportunity gaps in higher education.

\section{Mediating Opportunity Gaps in Higher Education}

There are two schools of thought that dominate the discourse involving opportunity gaps in higher education. The first is a deficit remediation model, which is focused on determining the needs of a student including concerns, defects, and deficits in order to design programs to "fix" students (Anderson, 2005). In some instances, students are required to enroll in remedial classes before they can pursue their personal degree interests (Anderson, 2005). Many needs or deficit-focused interventions for students of color involve peer groups and providing students with additional academic support and study opportunities. The second is a strengths-based model, which stresses the importance of a person's talents (Anderson, 2005). Talents are naturally occurring, unique aspects of a person that extends beyond IQ, aptitude, and academic ability (Anderson, 2005). Fully recognized talents can be developed into strengths and be applied to achievement tasks (Anderson, 2005). The idea behind a strengths-based approach is that students who are made aware of their talents/strengths and are taught to apply them will have a more fulfilling college experience, increasing student engagement, retention, and graduation rates. Recent arguments surrounding this issue are concerned with institutions as being a hinderance to economic and racial equality by emphasizing remedial approaches to student deficits (Bohanon, 2016). These approaches are highlighted in the next selection, beginning with the deficit remediation model.

\subsection{Deficit Remediation Model in Higher Education}

Research presented in this portion of the paper meet the definition of deficit-focused interventions as presented by Anderson (2005), although they are not explicitly stated as such in the literature. As mentioned, in a deficit-focused approach, efforts to mediate against dropout rates and increase academic engagement through a focus on deficits and/or needs of the students, rather than considering their strengths, are the norm. Literature associated with needs and deficits of students of color include creating feelings of belonging through peer groups as a mediator to on-campus racism, providing academic mentoring, increasing study opportunities, and providing remedial coursework. The literature will begin by discussing successful approaches that addressed the needs of students through a comprehensive manner. For instance, while having a peer group can be viewed as a strength, a program that seeks to create feelings of belonging on a campus that struggles with racism can be viewed as a deficit remediation approach as it seeks to minimize feelings of loneliness.

Factors that are attributed to the persistence and success of African American men in urban, public universities include having close relationships with peers of the same race to share experiences and mediate against experiences of overt racism (Strayhorn, 2017). Homogeneous peer groups may mediate against opportunity gaps between students of color and their white counterparts in colleges and universities. Brooms (2018) conducted 40 semi-structure, open-ended interviews with black males, 36 of which came from urban schools, regarding Black Male Initiative Programs featured at the historically white institutions they attend. These programs included, "The Brothers and Scholars Program" and the "Minority Men Mentoring Program," both of which are designed to increase student retention and student engagement (Brooms, 2018). Exclusive to these programs is the ability to meet and speak with other Black male students regarding lived campus experiences in an open, safe space (Brooms, 2018). As a result, students reported feeling a heightened sense of belonging. Feelings of belonging have been shown to relate strongly to engagement and retention rates (Soria \& Taylor, 2018). Tied to this was an increased sense of self where a group consciousness and collective identity helped to empower students by increasing accountability and responsibility for each other (Brooms, 2018). Another positive reported by interviewees was their sense of increased access to resources and human capital through interactions with mentors and institutional agents. Academic motivation was also fostered through opportunities outside of the classroom and academic supports provided by the programs (Brooms, 2018).

Blake and Moore (2004) believe that capable, academically prepared African American college students are 
falling behind during their first and second semesters of college due to distractions from social and sports-oriented activities (Blake \& Moore, 2004). Therefore, they created a comprehensive approach to increase the retention and graduation rates of African American college students at Iowa State University. Their first step was to create more academically rigorous courses, and in particular African American Literature, as high expectations have been shown to promote self-efficacy and time spent engaged in academic preparation (Blake $\&$ Moore, 2004). The professor for this course left detailed feedback on written assignments and students received encouragement to visit with the professor to discuss their progress (Blake \& Moore, 2004). In this case, the deficit or need is to increase academic focus.

In addition, students were also required to join one of three student support groups that were both homogeneous and heterogenous (Blake \& Moore, 2004). Undergraduate students led student support groups with participation from faculty, administrators and graduate students. Participation allows for cooperative study groups and mentoring programs (Blake \& Moore, 2004). Results showed that before the implementation of this program, African American students had a graduation rate of 27\% and 38\% between 1994 and 2000. By 2003, the graduation rates of this population increased to $44 \%$ (Blake \& Moore, 2004). The authors note that their greatest influence was on the persistence of students of color with the lowest academic performance, rather than an increase in academic success, indicating that the program reached those who were more likely to drop out (Blake $\&$ Moore, 2004). Students also may benefit from culturally relevant curriculum.

Hunn (2014) contends that predominately White colleges can promote a sense of belonging for African American students and simultaneously create a diverse curriculum. This author suggests that faculty can collaborate to create themes in courses and disciplines that are relevant to the African American experience (Hunn, 2014). From here, students are placed in a cohort of students that take the same classes and study outside of class together, to collaborate without a dependence on each other for their grades (Hunn, 2014). Then, in their second year, students begin working in team-based learning groups for group grades, something that requires trust and confidence, which is hopefully developed from the cohort model and interaction in the study group during the first year (Hunn, 2014).

Similarly, Fleming, Guo, Mahmood, \& Gooden (2004) conducted a study to determine the effects of a positive and culturally-relevant curriculum on the performance of African American college students on standardized and culturally-relevant classwork at Texas Southern University. Researchers used the Fast Track Program with students identified as vulnerable through their low scores (below 190) on the Texas Academic Skills Program TASP (Fleming et al., 2004). The Fast Track Program includes intensive two-hour math and reading blocks Mon-Fri where the classes are both highly interactive and culturally relevant (Fleming et al., 2004). The reading passage rate on the TASP went from $16.7 \%$ in the fall of 2001 to $100 \%$ in the spring of 2002 (Fleming et al., 2004). The authors suggest that having culturally relevant materials may increase reading ability for African American participants, allowing for these skills to transfer to their performance on standardized tests (Fleming et al., 2004). While these results are positive, other universities are joining forces to increase student retention and graduation rates through a more comprehensive approach.

Across the nation, universities are working together to increase student persistence. Under the University Innovation Alliance (UIA), 11 public higher education institutions in the United States (e.g. Arizona State University and Georgia State University) make up a consortium that are engaged in an exchange of best practices for retention and graduation rates of their college students (Bisoux, 2018). This membership has resulted in an increase in graduation rates by $24.7 \%$ and the completion of undergraduate degrees by $9.2 \%$ (Bisoux, 2018). From these positive outcomes, the UIA estimates a trajectory of 94,000 graduates by 2025 (Bisoux, 2018). In this selection, we will discuss some of the findings of recent initiatives implemented by universities associated with the UIA and, in particular their impact on students of color.

Dr. Tim Renick of Georgia State University (GSU) has looked at issues with persistence by considering how advising, class assignment, and financial burdens, to name a few, may impact this issue. He believes that personalized assistance is of paramount importance to increasing graduation rates (Renick, 2018). Meta Majors is an initiative at GSU involves placing students into cohorts, or Freshman Learning Communities (FLC), of no more than 25 students that share common academic interests (e.g. education and health) to minimize overwhelming feelings associated with navigating campus life (GSU: Meta-Majors, 2018). In addition, students at GSU that lack sufficient funds to pay for their courses may be eligible for the HOPE scholarship, which is awarded to students from families earning $\$ 30,000$ or less annually (GSU: Keep Hope Alive, 2018). However, students that qualify for this scholarship must maintain a 3.0 GPA (GSU: Keep Hope Alive, 2018). For students that may lose this opportunity, GSU has created additional assistance through Keep HOPE alive, which provides a \$500 stipend for two semesters as students work to get their GPAs in good standing (GSU: Keep Hope Alive, 
2018). Finally, through the GPS Advising Initiative, the University began to track undergraduates daily, receiving alerts regarding students that enroll in the wrong class or do poorly in a prerequisite course (GSU: GPS Advising, 2018). As a result of their initiatives, GSU not only graduated 1,700 more students compared to five years ago, they are increasing the graduation rates for minority students, essentially leveling the playing field (GSU: GPS Advising, 2018). Georgia State is ranked as number one, nationally, for graduating African American Students (GSU: Approach, 2018). GSU increased the African American graduation rate from 25.6\% to 58.4; Hispanic from $22 \%$ to $57.6 \%$ and White from $31.6 \%$ to $50.4 \%$ since 2003 . Most notably, their graduation data shows no "achievement gap."

The University of Texas (UT) has also seen positive outcomes from their initiatives. Their overall 4-year graduation rate increase from 52\% to 66\% in 2017 and, for students of color, 4-year graduation rates have improved from $43 \%$ to $60 \%$ for Hispanic populations and from $37 \%$ to $58 \%$ for African American students (Alvarad, Connerat, \& Smith, 2018). This success may be attributed to their Every Student Graduates initiative, which uses statistical analyses to predict which students will be the most at-risk (e.g. demographics or academic history) for dropping out and reach out to these students early on and connect them with resources (Alvarad, Connerat, \& Smith, 2018). Additionally, all freshmen are required to join interest groups of 20-25 students that have regular meetings with faculty and opportunities to participate in extracurricular activities (Haurwitz, 2017). Enrolled students are encouraged through messages regarding the importance of on-time graduation through UT's "Class of" campaign where they emphasize the year a student will graduate in all correspondences with students in effort to convey and promote 4-year graduation expectations for students (Alvarad, Connerat, \& Smith, 2018). UT also acknowledges that they must create seat availability for required classes and have faculty available if they need to open an additional course to meet student needs (Alvarad, Connerat, \& Smith, 2018). This ensures that students are able to take the courses they need to graduation on time.

In effort to increase on-time graduation, UT also provides the Path to Admission Through Co-Enrollment (PACE) program that acts as a bridge between community college and full-time enrollment at UT. In this case, students take one class their first year at UT while taking the bulk of their courses at the nearby community college (The University of Texas at Austin, 2018). The following year, students enroll full-time at UT and remain on track and on-time for graduation (The University of Texas at Austin, 2018).

The University of Texas has also been credited with initiating the Student Employment Initiative (SEI) as they recognized that working part time is essential to Hispanic students staying in college and graduating on time (Stern, 2014). The issue is that when students work part-time off campus, they may view themselves as being employees first and students second (Stern, 2014). To combat this, the University SEI program allows students to work part time on campus for 20 of fewer hours a week (Stern, 2014). In order to be accepted, students are required to have 12 credits hours with a minimum GPA of 2.75 (Stern, 2014). Students work in positions that are geared towards their majors and can make around nine dollars an hour as teaching assistants, doing research in labs, as English and Math tutors or in Human Resources and business affair departments (Stern, 2014). To improve the students' experience further, supervisors of these positions are trained as role models for the students (Stern, 2014). The program has shown to be successful with $95 \%$ of the 100 students in the program staying in college and graduating in 4.1 years, which is an improvement to their 5.7 average (Stern, 2014). Students' reports of the program were positive, stating that they gained experience that applied to their majors, strengthening their resume and ability to communicate (Stern, 2014).

Similar to GSU's GPS advising tool, Arizona State University (ASU) implemented eAdvisor, which tracks students and flags them when they engage in a behavior that could delay their graduation (e.g. not declaring a major) (Bisoux, 2018). Following this initiative, freshmen graduation rates at ASU increased by $9.5 \%$ and their six-year graduation rate increased by 19.3\%. (Bisoux, 2018). UIA contends that based on the positive results of these software enhancements across the campuses in the consortium, if every public institution of higher learning were to implement a predictive analysis system, the retention of 335,000 students could be realized (Bisoux, 2018).

While these universities have shown some success using deficit-remediation models, particularly with consideration to emotional and financial needs of students of color, deficit models that use remedial courses exclusively have not shown to be successful. Remedial college courses tend to cost universities a lot of money, with a reported $\$ 3$ billion being spent across the nation in 2011 and are not attributed to high retention and graduation rates (Complete College America, 2012). In fact, the opposite may be true. Around 20 percent of students enrolled in four-year universities are placed in remedial classes, and, often, these students, upset with their placement, may decide not to take classes at all (Complete College America, 2012). For those that stick around, about a third will earn a bachelor's degree in six years (Complete College America, 2012). This is 
particularly problematic for students of color where $39.1 \%$ of African American students and $20.6 \%$ of Hispanic students are placed in remedial courses (Complete College America, 2012). Of these, 69.5\% and 64.6\% of African American and Hispanic students completed remediation, respectively (Complete College America, 2012). Using co-requisite courses is thought to be a better alternative to remedial coursework that occurs in isolation, where students are given support in the form of built-in remediation, tutoring, and required self-paced computer labs full credit courses (Complete College America, 2012). Students are also encouraged to take courses that align with their program of study with embedded supports, as those that do are twice as likely to earn a degree or certificate (Complete College America, 2012).

Anderson (2004) contends a deficit-remedial approach can be demoralizing and stigmatizing to students, reducing motivation, increasing stereotypes, and lowering faculty and staff expectations. Faculty and staff may feel that working with students enrolled in remedial classes is moot as, in their view, many will not succeed and should not have been admitted to the university (Anderson, 2004). When faculty have this view, students may disengage and dropout as they feel stereotyped and that professors do not view them as capable. For these reasons, it may be more appropriate to address opportunity gaps through a strengths-based approach.

\subsection{Strength-based Approaches in Higher Education}

Strengths-based approaches to engagement and retention are gaining traction in higher education across the nation (Soria \& Taylor, 2016). This approach views students as having the potential and resources to be successful in their lives (Soria \& Taylor, 2016). Strengths-based education is accomplished through assessing, teaching and creating learning opportunities that allow students to realize their strengths and apply them in a way that promotes academic and personal achievement (Anderson, 2004). In this approach, it is not enough for the students to understand their strengths, the faculty and staff must be aware of their own abilities to strengthen their own instruction and remain current in their area of expertise (Anderson, 2004). Anderson (2004) contends that growth occurs when we are aware of individual talents, but many do not know what they excel in, limiting their potential. It is important to note that while a number of studies look at deficit-remedial approaches to addressing the needs of college students of color, a limited body of research examining strengths-based approaches to retention and graduation rates of this population. This section will examine literature associated with strengths-based models as related to retention and graduation rates of University students that may not generalize to all student populations, an issue that will be addressed later in this paper.

In a strengths-based approach in higher education, the first step is to have students and faculty take an assessment to determine their strengths. This can be accomplished through the Clifton StrengthsFinder, which has 34 talent themes associated with how a person thinks, feels, and behaves (Clifton \& Harter, 2003). For instance, a person can be strong in areas of communication, competition, empathy, and self-assurance (Clifton \& Harter, 2003). Those that take the assessment are made aware of their top five talents (Clifton \& Harter, 2003). Strengths are achieved when talents are maximized, or when they are combined with a persons' knowledge and skills and repeated ability to perform a specific task (Clifton \& Harter, 2003). Clifton and Harter (2003) contend that a person will be much more successful when they have the opportunity to build on their strengths rather than focusing on remediation of their weaknesses. When students know their strengths, they can more easily determine a major that aligns with their abilities and allows for increased levels of collaboration through respect for others' strengths (Lopez, 2014).

Indiana University-Purdue University Indianapolis in Indiana (IUPUI), a member of the UIA consortium, is using strengths-based coaching in effort to retain and graduate more of their students (Bisoux, 2018). Since Smart Phones are an easy way to get in touch, coaches are not only meeting with students face-to-face, but they are connecting with students through ongoing email and texts as well (Bisoux, 2018). This approach may increase the level of communication with students. IUPUI also assists students in developing "non-cognitive" skills, such as time management, factors that are attributed to success rates of students (Bisoux, 2018). As a result of these efforts, students' graduation rates at IUPUI increased from an average of $50 \%$ to $63 \%$ (Bisoux, 2018).

Additional success with a strengths-based approach was noted at a University in the Midwest where incoming freshman were invited to take the StrengthsFinder, learn their five talents, and engage in opportunities to engage in discussions with peers, faculty, and advisors regarding their strengths (Soria \& Stubblefield, 2014). Students also took a survey to determine their knowledge of their individual strengths. Findings associated with the strengths-based approach were positive (Soria \& Stubblefield, 2014). First year students that participated were $91.5 \%(\mathrm{n}=4,563)$ more likely to be retained into the next year than their counterparts who did not $(88 \%, \mathrm{n}=227)$ (Soria \& Stubblefield, 2014). Those that showed an awareness of their strengths and participated in 
conversations with the college community were more likely than their peers to be retained into their second year (Soria \& Stubblefield, 2014). Forty-four percent of those that participated in conversations reported higher levels of self-efficacy (Soria \& Stubblefield, 2014). Findings associated with the strengths-based approach do not disaggregate by race. In some cases, student's that live on college campuses may struggle with engagement and retention.

Soria and Taylor (2016) conducted a study to determine the impact of a strengths-based approach to interaction in housing on student engagement and second year retention rates on an urban campus in the upper-Midwest of the United States. Prior to their first year, students and Community Advisors take the Clifton StrengthsFinder assessment to determine their top five strengths (Soria \& Taylor, 2016). In addition, Community Advisors were trained as strength educators and created engagement and workshop opportunities to teach students how to use their five strengths (Soria \& Taylor, 2016). Students were also engaged in strength-based conversations with resident directors and encouraged to post their five strengths on the outside of their dorm room door (Soria \& Taylor, 2016). Students that participated were more likely to report student engagement and had a higher second year retention rates when compared to those who did not participate in strength-based experiences (Soria \& Taylor, 2016). It is important to indicate that the population of this sample were $75.3 \%$ White, $3.4 \%$ Black, and $2.8 \%$ Hispanic or Latino, and, therefore, cannot be generalized to minority students. More research is necessary to determine how to increase persistence for students of color in institutions of higher learning.

\section{Implications for Policy Development and Practice}

In order to address opportunity gaps between students of color and their White counterparts in institutions of higher learning, a comprehensive approach is needed. Programs that have been successful in addressing opportunity gaps focus on creating feelings of belonging, implementing a culturally responsive curriculum, and considering the strengths of students. Such initiatives begin by creating peer groups, providing access to human capital and high-quality mentorships from faculty of color, as well as having strengths-based conversations with peers, faculty, and staff. To truly meet the needs of all students, it may be irresponsible to consider students' weaknesses without considering their strengths or vice versa. Moreover, a truly comprehensive approach should first look internally, at potential barriers at the institutional level, rather than emphasizing deficits that reside in the student as a dominant factor impacting the persistence of students of color.

Opportunity gaps between students of color and their White counterparts persist despite decades of a deficit-remediation approach. A focus on remedial classes has proven to be detrimental to the success students, and in particular, students of color (Anderson, 2004). As Anderson (2004) contends, faculty may not invest much into students taking remedial courses, as they may not believe that they are capable of success. Additionally, remedial coursework is not included in a student's program and therefore increases the amount of time that it may take to graduate, potentially causes additional financial strain. This is not to say that incoming freshman should not receive assistance when they may require prerequisite knowledge in order to be successful. Perhaps a more viable option would be to either embed remediation into required coursework and/or allow remedial classes to count as electives. To combat financial deficits, there have been some successes when the focus on the needs of the students is considered with respect to their financial well-being.

As shown in the literature, focusing on the financial needs of minority students showed an increased rate of retention and graduation rates for students of color. At the same time, it is important to provide financial options for all students, not only those with high GPAs or test scores. A limitation of the SEI at the University of Texas is that it focused on those that had a GPA of 2.75 or higher and were enrolled in, at minimum, 12 credit hours (Stern, 2014). This limits the potential of students that do not meet this criterion. A program that wishes to increase the retention and graduation rates of all students may be more inclusive of students, regardless on their GPA, in interventions that provide financial assistance. Further, financial assistance may not be enough to rectify inequitable outcomes between students of color and their White counterparts when issues exist within the institutions that may perpetuate issues associated with persistence of students of color.

Blatant, implicit, and institutional racism continues to be a barrier to success for students of color at the university level. Blake and Moore (2004) revealed that homogenous peer groups that provide a safe place to vent frustrations could create feelings of belonging and increase retention and graduation rates for students of color. Although this is a needs-based approach, it is clear the researchers have a valid point. Feelings of isolation can increase the likelihood of that a student will drop out and racial tension on a predominately White campus can trigger these emotions (Blake \& Moore, 2004). However, the onus of minimizing feelings of loneliness on campus should not fall entirely on those that are marginalized. Having homogenous peer groups can improve the success rates of students of color, but university leaders may consider approaches to creating a safe campus that 
does not tolerate racism in any form. For that to be possible, we must increase the cultural competencies and diversity of faculty.

Hiring opportunities must be extended to a diverse pool of candidates. While many apply for positions in higher educations, many employers look for those with similar backgrounds, either consciously or subconsciously, in terms of race and educational background, such as the universities they attended. Creating a homogeneous faculty may maintain the status quo; create distance with students, and limit perspectives and opportunities for personal and collective growth (Moragne-Patterson \& Barnett, 2017). As a result, a number of universities are launching initiatives to increase faculty diversity (Paterson, 2018). For instance, California University restructured their hiring process using an anti-bias checklist that focused on job announcements, application reviews, reference checks, phone interviews, and choosing finalists, which all need to be confirmed by the dean (Paterson, 2018). Similarly, Bentley University now requires a two-hour workshop regarding implicit and individual bias for those on search committees (Paterson, 2018). Across the nation, universities have a predominately White faculty, and this can be problematic during the hiring process when trying to create a more diverse campus. Therefore, it is important that universities continue to develop initiatives to increase the likelihood that they will hire qualified candidates that may have different backgrounds, cultures, and ideals than the majority.

Diversifying faculty at institutions of higher education may also help create more culturally relevant curriculum. As Hunn (2014) discovered, including common themes across courses that are culturally relevant and diverse increased success rates for students of color. Universities should evaluate their courses to ensure that the curriculum is inclusive. This could be accomplished by having faculty from diverse backgrounds teach courses and presenting research completed by individuals with multiple perspectives and experiences. Perhaps the lack of diversity among faculty also creates initiatives focused on the deficits/needs more than the strengths of students of color. To date, the literature regarding strengths-based approaches to retention and graduation rates is limited, and for students of color, it is non-existent.

Strengths-based approaches that use the Clifton Strengths Finder to help students understand their strengths have shown to be successful with White students. When students learn what their strengths are and actively engage in conversations with faculty, advisors and peers, retention and graduation rates have been shown to improve (Soria \& Taylor, 2016; Soria \& Taylor, 2014). In order to truly determine the effectiveness of this model, the Strengths-based intervention should also be extended to focus on minority populations. However, given that the literature on the deficits approach model show some promise for students of color in terms of emotional wellbeing and financial aid it may not be a viable option to completely do away with addressing student needs. With respect to the literature, a more effective approach may need to address institutional barriers first and foremost while emphasizing the strengths of its students.

GSU and ASU are both examples of universities that are addressing programming issues. One way they are increasing student success is by streamlining advising by making it more responsive. Advisors are alerted when students fail to enroll in a class, do poorly on an exam, or miss classes. It is not enough to wait for students to contact advisors when they are struggling, particularly for students of color who are also more likely to be first-generation students and, therefore, may not know how to effectively navigate a university environment. As such, universities that wish to retain students may see better results if they reach out to students as soon as a problem arises and follow-up frequently. With increased student use of technology, advisors may wish to offer additional modalities for communication, including Skype and text messages to increase availability.

Advising efforts can also be improved if there is a focus on strengths-based conversations to allow students to make decisions regarding their major and minor choices based on the areas in which they excel. Students may be required to meet with advisors before beginning their program to discuss their strengths and goals. A hinderance to degree completion is changing majors. Early conversations with advisors that focus on strengths may mediate against this issue.

Universities must also convey high expectations in order to increase the persistence of all students, including those of color. The University of Texas has high expectations for their students with their "Class of Campaign" (Haurwitz, 2017). As mentioned, this initiative reminds students frequently of their projected graduation date in effort to encourage students to graduate in four years (Haurwitz, 2017). Additionally, high expectations can be portrayed through an academically rigorous curriculum and by leaving detailed feedback on assignments to allow for academic improvement (Blake \& Moore, 2004). A university may adopt a growth mindset where a focus on improvement is the norm. In this case, students would have opportunities to correct assignments and retake tests until they receive a satisfactory grade. This flips the expectation from a focus on grades to a focus on 
learning.

Findings from both the deficit-approach models and the strengths-based approach show some promise and proven success rates. First, financial aid considerations that do not only focus on students with high GPAs are necessary to promote graduation and retention of students. Fostering a sense of belonging through cohorts of students and homogeneous peer groups were also related to student persistence. Additionally, effective and timely advising efforts (e.g. GPS advising and eAdvisor) must be in place to help students that begin to show difficulties early on to increase retention and graduation rates of their students. This ensures that students stay on track for graduation and also conveys the message that the university cares about its students. It is important to point out that while the presented universities and research regarding student persistence are attending to programming deficits in terms of advising in effort to enhance student persistence, the majority of initiatives still focus on student deficits (e.g. financial assistance and student support groups). While these initiatives have been shown to have positive outcomes, a comprehensive approach may be needed to reach all students. Institutions of higher learning must address programmatic issues across campuses in the United States that may hinder the academic progress of students of color and place more emphasis on strengths-based initiatives. Combined, these interventions may lead to more positive campus environments and an increase in persistence for all students, including those of color. Literature contained within this document has been used to inform how Cleveland State University will address issues associated with opportunity gaps in higher education.

\section{Promising Programming at Cleveland State University: Developing a Comprehensive Strategy}

Consistent with the literature, students arrive at Cleveland State University (CSU) with different backgrounds, strengths and pre-college experiences that affect their academic performance, however these characteristics of students interact with the characteristics of the institutions they attend. Thus, a student with a given set of characteristics (demographics, test scores, high school experiences) will be more successful in some institutions than others because of differences in institutional approach, culture and resources. An effective plan to improve student outcomes must recognize that those outcomes are the result not of deficiencies in students but of the interaction between student characteristics and the institutions they attend.

At Cleveland State University, we are looking at new ways to increase the persistence of students of color with a particular focus on how its programming may hinder student success. To meet this goal, we have examined comparable public institutions that have been successful in mediating against inequitable retention and graduation outcomes between students of color and their White counterparts. In order to address barriers to educational opportunities and persistence of students of color, Cleveland State University intends to create an initiative that looks at the issue comprehensively. While the initiative will consider what the needs of the students are, CSU seeks to move beyond an emphasis on student deficits where we blame the student, with an emphasis on what programmatic issues may exist at the university level that can contribute to barriers to retention and graduation of students of color. Additional aspects of our initiative will also consider the strengths of our students. These additions make CSUs program qualitatively different than other programs that have focused, predominately, on the deficits of their students.

\subsection{Mitigating Barriers to Persistence: The Collaborative Problem-Solving Process}

Collaborative problem-solving process will result in the conceptualization and development of a comprehensive strategy to better address students of color persistence rates at CSU. Throughout this initiative, the contribution of all relevant stakeholders - university faculty, administrators, and community-based organizations-were deliberately solicited, considered, and integrated into the problem-solving and conceptualization process. The anticipated end result of this initiative will be the establishment of a comprehensive diversity action plan, and also a greater awareness of the conditions that are vital for the student success at CSU. In anticipation of the collaborative problem-solving process, the President's Council on Diversity (PCD) was established. Initial stages of the reform process include identifying key variables that will facilitate such a large initiative. The PCD identified several key criteria that will contribute to this effort, including (a) breaking down unit silos, (b) reciprocity, (c) awareness of existing efforts to improve retention and graduation rates of student of color, and (d) transparency. The following briefly describes each criterion in the collaborative process.

\subsubsection{Breaking down Unit Silos}

The success of student initiatives depends on the ability to access and apply the collective expertise of pertinent stakeholders, campus and community wide. Critical to this process is breaking down environmental silos and inviting collaborative dialogue amongst concerned parties to achieve the greater goal, in this regard improving persistence rates of student of color. As such, identifying barriers to persistence requires a collective effort to honestly identify and consider systemic issues that impede student progress. In addition, by breaking down silos 
we were also more aware of the work that was already happening on campus. Identifying duplication of services, and which initiatives were not being monitored for progress, for instance, need to be considered. It is our hope that such discussions will improve our ability to collaborate and maximize resources to better support students of color in graduating.

\subsubsection{Reciprocity}

There exists an inherent criticism against the ineffectiveness of the unidirectional interactions that dominate university partnerships, specifically the partnership between university faculty and administration. This arrangement will not only serve to increase the disconnection between pedagogical instruction and pedagogical practice but will also foster a climate of distrust between the university and administrators in which decisions are typically made with regard to service provision that ultimately impact subsequent student success or lack thereof. Addressing this discrepancy required a reconceptualization of this relationship. The previously-utilized monologue of "take" is to be replaced by that of reciprocity; the PCD was established in an unique arrangement to bring administrators, faculty, and community-based organizations together to work closely with each to review student outcome data, to engage in discussion around owning and accepting our role in the continued inequities in student performance outcomes that are racially based, identify and honestly consider how current practices impede student success, establish benchmarks that were aspirational, actionable and obtainable across time, and identify evidenced-based initiatives that will break down and or eliminate systemic barriers that impede or work against timely program completion. In other words, reviewing the data, owning our part in putting up barriers for certain groups of students and identifying ways to change how the system works to ensure timely and/or on time graduation. This approach was best accomplished through frequent and open communication between all relevant stakeholders.

\subsubsection{Awareness of Existing Efforts to Improve Retention and Graduation Rates of Student of Color}

Great efforts will be made to investigate existing models and initiatives, both within Urban Institutions of Higher Education (IHE) across the country as well as other fields of study that embraced a collaborative problem-solving process. Specifically, the PCD members' research best practices in place at other institutions to increase the graduation rate of African Americans and Latinx students in an effort to discover which elements would best be applied at CSU. From this, the research team will be able to address a number of pragmatic issues with respect to not only the theoretical considerations of curriculum redesign, but also a number of pragmatic concerns with respect to the recruitment, retention, advising, impact of faculty of color, and creating a system grounded in data-based decision making resulting in better evaluation of initiatives that are currently in place to inform future modifications and dissemination.

\subsubsection{Transparency}

Finally, it is critical that university faculty, students, staff and administrators who would be directly impacted by student success initiatives be continuously made aware of the process and invited to share suggestions and concerns. Utilizing available technologies (i.e., discussion board and website postings) as well as more traditional means of communications (frequent face-to-face updates during faculty meetings) will facilitate the endorsement of the proposed changes. The deliberate openness of this process served to quell concerns and dispel misconceptions, which we believe will bring about a greater level of University and greater community engagement.

\section{Conclusions}

As indicated, barriers to educational opportunities at institutions of higher learning for students of color exist and these institutional barriers are often overlooked when looking to improve retention and graduation rates of marginalized populations. Universities more often consider the deficits of their students as the most dominant predictor of student outcomes. We believe this neglects the potential strengths of students and absolves the university of any responsibility or wrongdoing. Cleveland State University is working to flip this line of thinking by engaging in a collaborative problem-solving approach. By acknowledging the deficits in our programming at Cleveland State University and the strengths of our students first, we are working to dismantle notions that deficits only reside in students while moving toward increased equitable student success outcomes and graduation rates for African American and Latinx students.

\section{References}

Alvarado, C. G., Connerat, C., \& Smith, J. (2018). Every student graduates: The University of Texas at Austin strategies to increase graduation rates 2012-2017 (Unpublished doctoral dissertation). The University of Texas at Austin: Austin, TX. 
Anderson, E. (2005). Strengths-based educating: A concrete way to bring out the best in students-and yourself: The confessions of an educator who got it right-finally!. Educational Horizons, 83(3), 180-189.

Anderson, E. C. (2004). What is strengths-based education?: A tentative answer by someone who strives to be a strengths-based educator. Unpublished manuscript, Educational Leadership, Azusa Pacific University, Azusa, CA. Retrieved from https://strengths.uark.edu/documents/what-is-strengths-based-education.pdf

Aud, S., Wilkinson-Flicker, S., Kristapovich, P., Rathbun, A., Wang, X., \& Zhang, J. (2013). The Condition of Education 2013. NCES 2013-037. Washington, DC: National Center for Education Statistics.

Bisoux, T. (2018). First-Generation Strategies: How higher education can clear away obstacles and open doors to better serve underrepresented student populations. BizEd. Retrieved from https://bized.aacsb.edu/articles/2018/06/first-generation-strategies?utm_source=Higher+Ed+Innovation+Bu lletin\&utm_campaign=455732c345-EMAIL_CAMPAIGN_2018_07_05_COPY_01\&utm_medium=email \&utm_term=0_7efeb67cd3-455732c345-142309393

Blake, J. H. \& Moore, E. L. (2004). Retention and graduation of Black students: A comprehensive strategy [Monograph]. Higher Education, 63. Retrieved from http://www.cehd.umn.edu/crdeul/pdf/monograph/5-a.pdf\#page=73

Brooms, D. R. (2018). 'Building us up': Supporting black male college students in a black male initiative program. Critical Sociology, 44(1), 141-155. doi:10.1177/0896920516658940

Census Bureau. (2011). 2010 Census redistricting data (public law 94-171) summary file, tables p1 and p2. Washington, DC: Author. Retrieved from https://www.census.gov/prod/cen2010/doc/p194-171.pdf

Cerezo, A., \& Mcwhirter, B. T. (2012). A brief intervention designed to improve social awareness and skills to improve Latino college student retention. College Student Journal, 46(4), 867-879.

Clifton, D. O., \& Harter, J. K. (2003). Strengths investment. In K. S. Cameron, J. E. Dutton, \& R. E. Quinn (Eds.), Positive organizational scholarship. (pp. 111-121). San Francisco: Berrett-Koehler.

Complete College America (n.d.). Corequisite support. Washington, DC: Author. Retrieved from https://completecollege.org/strategy/corequisite-support/

Complete College America. (2012). Remediation: Higher education's bridge to nowhere. Washington, DC: Author. Retrieved from https://www.insidehighered.com/sites/default/server_files/files/CCA\%20Remediation\%20ES\%20FINAL.pdf

Debb, S. M., Colson, D., Hacker, D., \& Park, K. (2018). Applying the Connor-Davidson Resilience Scale for Use with Third-Year African American College Students. Journal of Negro Education, 87(1), 73-89.

Dulabaum, N. L. (2016). Barriers to academic success: A qualitative study of African American and Latino male students. League for Innovations, 11(6). Retrieved from

https://www.league.org/innovation-showcase/barriers-academic-success-qualitative-study-african-americanand-latino-male

Duranczyk, I. M., Higbee, J. L., \& Lundell, D. B. (2004). Best practices for access and retention in higher education. Center for Research on Developmental Education and Urban Literacy, University of Minnesota.

Fleming, J., Guo, J., Mahmood, S., \& Gooden, C. R. (2004). Effects of Multicultural Content on Reading Performances. Higher Education, 55, 65-92. Retrieved from

https://conservancy.umn.edu/bitstream/handle/11299/5363/mono5.1.pdf?sequence=2\#page=65

Gear up Ohio. (n.d.). Ohio Higher Education. Retrieved from https://www.ohiohighered.org/gearup

GSU: GPS Advising. (n.d.). Georgia State University. Retrieved from https://success.gsu.edu/initiatives/gps-advising/

GSU: Keep Hope Alive. (n.d.). Georgia State University. Retrieved from https://success.gsu.edu/initiatives/keep-hope-alive/

GSU: Meta Majors (n.d.). Georgia State University. Retrieved from https://success.gsu.edu/initiatives/meta-majors/

Harper, S. R., Patton, L. D., \& Wooden, O. S. (2009). Access and equity for African American students in higher education: A critical race historical analysis of policy efforts. The Journal of Higher Education, 80(4), 389-414. Retrieved from

https://repository.upenn.edu/cgi/viewcontent.cgi?referer=https://www.bing.com/\&httpsredir=1\&article=121 
$0 \&$ context $=$ gse_pubs

Haurwitz, R. K. M. (2017). UT's 4-year graduation rate rises, but still falls short of $70 \%$ goal. My Statesman. Retrieved from https://www.mystatesman.com/news/local/year-graduation-rate-rises-but-still-falls-short-goal/SCgF3wG42r wMzWxQ4G7a4M/

Hunn, V. (2014). African American students, retention, and team-based learning: A review of the literature and recommendations for retention at predominately white institutions. Journal of Black Studies, 45(4), 301-314.

Keels, M. (2013). Getting them enrolled is only half the battle: College success as a function of race or ethnicity, gender, and class. American Journal of Orthopsychiatry, 83(2pt3), 310-322.

Lopez, S. J. (2014). A good job is hard to find ... Until students know what they do best. About Campus, 19(1), 2-6.

Louis, M. C. (2011). Strengths interventions in higher education: The effect of identification versus development approaches on implicit self-theory. The Journal of Positive Psychology, 6(3), 204-215.

Martinez, B. C., \& Martinez, M. J. (2016). Latino student success pilot at Rhode Island college: Research findings and recommendations. Executive summary. Annenberg Institute for School Reform at Brown University. Retrieved from http://eric.ed.gov/

Moragne-Patterson, Y. K., \& Barnett, T. M. (2017). Experiences and responses to micro-aggressions on historically white campuses: A qualitative interpretive meta-synthesis. Journal of Sociology \& Social Welfare, 44(3), 3-26.

National Center for Educational Statistics. (2015). Fast Facts. Washington, DC: Author. Retrieved from https://nces.ed.gov/fastfacts/display.asp?id=61

Ohio State News. (2011). Minority retention, graduation rates at Ohio State exceed national marks. Retrieved from https://news.osu.edu/minority-retention-graduation-rates-at-ohio-state-exceed-national-marks/

Panther Retention Grant. (n.d.). Georgia State University. Retrieved from https://success.gsu.edu/initiatives/panther-retention-grants/

Patterson, J. (2018, June 28). New approaches to boosting faculty member diversity. Education Dive. Retrieved from https://www.educationdive.com/news/new-approaches-to-boosting-faculty-member-diversity/526625/

Renick, T. (2018). Leading with predictive analytics. Georgia State University. Retrieved from https://success.gsu.edu/approach/

Reynolds, C. V. (2012, March 17). No Man Left Behind. Chronicle of Higher Education, 58(28), 20-28.

Ross, T., Kena, G., Rathbun, A., KewalRamani, A., Zhang, J., Kristapovich, P., \& Manning, E. (2012). Higher education: Gaps in access and persistence study (NCES 2012-046). Washington, DC: National Center for Education Statistics.

Rowell, L. \& Prescott, V. (2018). How Georgia State University became a beacon of change for higher education everywhere. GPB Radio News. Retrieved from http://gpbnews.org/post/how-georgia-state-university-became-beacon-change-higher-education-everywhere

Russon, G. (2016, August 19). Software to help UCF advisers keep students on track. Orlando Sentinel. Retrieved from http://www.orlandosentinel.com/features/education/os-ucf-counseling-software-20160502-story.html

Sawhill, I. V. (2013). Higher education and the opportunity gap. Brookings. Retrieved from https://www.brookings.edu/research/higher-education-and-the-opportunity-gap/

Shapiro, D., Dundar, A., Huie, F., Wakhungu, P., Yuan, X., Nathan, A \& Hwang, Y., A. (2017). A national view of student attainment rates by race and ethnicity: Fall 2010 cohort (Signature Report No. 12b). Herndon, VA: National Student Clearinghouse Research Center.

Sinanan, A. (2016). The value and necessity of mentoring African American college students at PWI's. Journal of Pan African Studies, 9(8), 155-166.

Soria, K. M., \& Stubblefield, R. (2014). First-year college students' strengths awareness: Building a foundation for student engagement and academic excellence. Journal of the First-Year Experience \& Students in 
Transition, 26(2), 69-88.

Soria, K. M., Laumer, N. L., Morrow, D. J., \& Marttinen, G. (2017). Strengths-based advising approaches: Benefits for first-year undergraduates. NACADA Journal, 37(2), 55-65.

Stern, G. M. (2014). Part-time job program for Latinos boosts college success. Education Digest, 79(9), 55-58.

Strayhorn, T. L. (2017). Factors that influence the persistence and success of black men in urban public universities. Urban Education, 52(9), 1106-1128. doi:10.1177/0042085915623347

Tinto, V. (2016). How to improve student persistence and completion. Inside Higher Education. Retrieved from https://www.insidehighered.com/views/2016/09/26/how-improve-student-persistence-and-completion-essay

US Census Bureau (2001). Census 2000 Redistricting Data (Public Law 94-171) Summary File, Tables PL1 and $P L 2$. Washington, DC: Author. Retrieved from https://www.census.gov/rdo/data/redistricting_data.html

US Census Bureau (2011). Census 2000 Redistricting Data (Public Law 94-171) Summary File, Tables PL1 and PL2. Washington, DC: Author. Retrieved from https://www.census.gov/prod/cen2010/doc/p194-171.pdf

Wagner, J. M. (2015). Hispanic minority college students at selective colleges: What matters with degree completion? Journal of Hispanic Higher Education, 14(4), 303-326.

\section{Copyrights}

Copyright for this article is retained by the author(s), with first publication rights granted to the journal.

This is an open-access article distributed under the terms and conditions of the Creative Commons Attribution license (http://creativecommons.org/licenses/by/4.0/). 